\title{
A retração da acumulação urbana nas cidades brasileiras: a crise do Estado diante da crise do mercado
}

\author{
Urban accumulation downturn in Brazilian cities: \\ the state crisis in view of the market crisis
}

Suely Ribeiro Leal

\section{Resumo}

A sintonia entre a crise econômica do estado brasileiro e a crise do mercado imobiliário leva à hipótese de estar havendo uma retração do processo de acumulação urbana nas cidades brasileiras. Ambas se situam no contexto da crise econômica mundial que têm afetado os países capitalistas desenvolvidos e periféricos desde 2008. No Brasil, essa crise tem se associado a uma crise de governabilidade política, que vem tendo impactos nos arranjos de governança pautados nas parcerias público-privadas e em modelos de empreendedorismo que deram sustentação aos grandes projetos urbanos veiculados pelas políticas de planejamento estratégico em estados e municípios metropolitanos nos anos recentes. Este artigo avalia a capacidade de sustentação da dinâmica da acumulação urbana diante da retração da produção imobiliária.

Palavras-chave: acumulação urbana; grandes projetos; mercado imobiliário; crise de governabilidade; empreendedorismo; Estado.

\begin{abstract}
The simultaneity between the economic crisis of the Brazilian state and the crisis of the real estate market raises the hypothesis that there has been a downturn in the urban accumulation process in Brazilian cities. Both crises are situated in the broader context of the global economic crisis that has been affecting developed and peripheral capitalist countries since 2008. In Brazil, it has been associated with a political governability crisis that has had implications for governance arrangements based on public-private partnerships, and also for entrepreneurship models that have supported large urban projects conducted by strategic planning policies in states and metropolitan municipalities in recent years. This article evaluates the sustainability capacity of the urban accumulation dynamics in view of the downturn in real estate production.
\end{abstract}

Keywords: urban accumulation; large projects; real estate market; governability crisis; entrepreneurship; State. 


\section{Introdução}

As reflexões que norteiam este artigo se situam no âmago das mudanças que vêm ocorrendo no espaço das cidades no contexto da dinâmica do Estado, da economia e da sociedade brasileira contemporânea, no qual são identificados novos atores globais que exercem o papel de agenciadores e interlocutores dos interesses do capital na esfera da produção do espaço urbano. A importância dos estudos sobre as tendências da ação do mercado imobiliário se deve ao papel, cada vez mais vigoroso, que esses atores vêm desempenhando como principais indutores da reconfiguração e produção do espaço e do processo de acumulação urbana das cidades brasileiras (Abramo, 2007; Leal, 2006, 2008a e 2008b).

Os impactos causados pela globalização e mundialização do capital sobre as cidades não são novos, particularmente em países em desenvolvimento, onde a segregação socioespacial sempre foi um marco da urbanização. A acumulação do capital, conforme especifica Harvey (2004, p. 88), é um evento histórico e geográfico que tem como função construir, destruir e reconstruir a cidade à sua semeIhança. Nesses termos, a transformação da cidade passa a ser um fator implícito à reprodução do capital em épocas do ciclo de sobreacumulação, representando uma destruição criativa na paisagem da acumulação do capital (Chesnais, 1996; Sassen, 1998; Harvey, 2004, 2005 e 2009).
0 foco de nossa indagação reporta-se ao comportamento dos atores que comandam a dinâmica do mercado imobiliário no sentido de provimento da oferta de megaprojetos urbanos e das demandas por eles geradas, levando em conta que há um emaranhado de redes de agentes econômicos globais que se imiscuem nos circuitos financeiros dos mercados locais monopolizados, no provimento desses tipos de empreendimentos. Nesse contexto, intervenções físicas de grande impacto, sustentadas por vultosos investimentos públicos e privados e associadas à construção de uma imagem atrativa da cidade para o mercado global, caracterizam um modelo de desenvolvimento apoiado no que Harvey denomina empreendedorismo urbano.

Os interesses econômicos, voltados para a disputa pelos investimentos dos mercados imobiliário e financeiro articulados entre si na nova ordem mundial, têm o Estado como forte mediador que atua oferecendo as condições requeridas à sustentação da acumulação urbana capitalista e, em paralelo, instaurando canais de participação voltados para 0 atendimento pontual de demandas de caráter emergencial dos segmentos populares. Se, conforme Harvey, é na governança urbana, isto é, na coalizão de forças mobilizadas por diversos agentes sociais, que se origina o poder de organizar o espaço, cabe questionar: que tipo de governança tem conduzido prioritariamente a política urbana nas metrópoles brasileiras? Trata-se de uma postura estratégica adotada pelo Estado para legitimar-se como poder ordenador da sociedade? 


\section{Paradigmas do neoliberalismo: menos Estado, mais mercado}

0 avanço nas duas últimas décadas dos paradigmas que orientam o neoliberalismo - menos Estado (menos regulação, menos planejamento) e mais Mercado - veio a fortalecer a ação empresarial e empreendedora nas cidades brasileiras pela via dos governos locais e estaduais. As novas formas de governança urbana no exercício do poder e o fortalecimento da relação entre o público e o privado daí derivado intensificaram a dinâmica da acumulação urbana. Um marco desse tipo de governança foi a associação entre atores privados e administrações públicas na implantação ou gestão de grandes projetos urbanos. É fato, também, que esse modelo de gestão exige que o mercado e seus atores se aliem em formatos de governança corporativa, de modo a tornar seus negócios mais seguros e expostos a menores riscos, além de propiciar a harmonização dos interesses corporativos, fator decisivo para a ampliação da confiança dos investidores (Andrade e Rossetti, 2009).

Para o bom funcionamento desses formatos de governança, é de fundamental importância a presença do Estado, como elo de equilíbrio na regulação dos recursos e no provimento das infraestruturas que estimulem a presença dos grandes grupos na produção do solo urbano. Distintamente dos meios tradicionais de regulação de políticas públicas, o papel do Estado no estabelecimento de parcerias voltadas para viabilizar os grandes projetos surgidos nos anos recentes, pauta-se por promover intervenções que envolvem mudanças significativas no espaço urbano. Para Oliveira (2012, p. 79):
[...] grandes projetos - entendidos como aqueles capazes de promover rupturas significativas nas formas de reprodução e apropriação social do espaço urbano têm características próprias que mobilizam novas justificativas e novos processos de legitimação para a articulação entre governos e interesses privados para a operação de transformações no ambiente construído, além de novas formas de planejamento e práticas específicas de relacionamento entre governos, empresariado e a população em geral.

Nas condições acima mencionadas, os meios urbano e social veem-se transformados por intervenções de natureza técnica e política nas quais os agentes econômicos se moldam pelo ideário do empresariamento, afetando a geografia do espaço e de seu território e permitindo o acesso do econômico aos meandros de todas as esferas da vida coletiva.

0 capitalismo assume novas formas de hegemonia capitaneadas pelo capital financeiro, o qual passa a impor suas influências na dinâmica econômica, provocando instabilidade e induzindo uma constante reanimação do consumo e da ação produtivista na administração pública e nas instituições sociais. A capacidade do econômico de se imiscuir em toda parte caracteriza a acumulação urbana comandada pelo capital financeiro, trazendo riscos de apatia e de indiferença social e de medo, de aumento da violência e de destruição de valores democráticos da cultura urbana.

Conforme afirma Harvey (1996), a acumulação urbana depende da destruição criativa e da subordinação de formas de produção e consumo, da difusão de valores culturais que fortaleçam a competitividade, da sucção de mais-valia gerada em escalas que transcendem 
a cidade, do controle de processos de valorização da terra urbana, da incorporação de conhecimento técnico no aumento da produtividade, da destinação de parte significativa da poupança das famílias e do capital público à expansão da produção, do acesso a valores de uso pela via exclusiva do mercado, e de convenções que estabeleçam a equivalência entre as mercadorias, incluindo o trabalho.

Os grandes projetos urbanos, apesar de suas diferenças, particularizam em conjunto a evolução recente da acumulação urbana: shoppings centers, condomínios fechados, prédios de escritórios e edifícios inteligentes e, com certo exagero, áreas revitalizadas, áreas estas que, por suas emissões estéticas unívocas, podem adquirir características similares às do objeto.

Esses tipos de projetos entraram em efervescência na década passada e foram viabilizados, sobretudo, por meio de parcerias entre atores privados e administrações públicas para a implantação ou gestão de grandes projetos urbanos. Foram responsáveis pelo intenso acirramento da acumulação urbana nas metrópoles brasileiras, tendo como vetores principais o mercado imobiliário e o capital financeiro. E foram desencadeados em formas diversas, a exemplos de bairros e cidades planejadas, revitalização de áreas centrais, processos de incorporação e transformação da estrutura fundiária e de geração e apropriação de mais-valias imobiliárias em áreas rurais, projetos urbanísticos e arquitetônicos associados a obras de infraestrutura, etc.

Onde esses projetos vigoraram, provocaram impactos muitas vezes danosos sobre os espaços físico, social e ambiental, além de terem contribuído para a consolidação de mudanças na dinâmica espacial, política, institucional, etc.

Uma crítica que pode ser dirigida às parcerias originadas por esses projetos é sobre 0 ônus oriundo dos investimentos e riscos que recai, sobretudo, sobre o poder público. Como afirma Harvey (ibid., p. 27), "os regulados começam a escrever as regras da regulação, enquanto o modo de tomada de decisão 'público' se torna cada vez mais opaco". Desse modo, na parceria público-privada há uma pactuação entre o Estado e o mercado, visando a garantir o aumento da acumulação do capital.

A emergência da crise econômica mundial e a consequente tendência à queda na taxa de lucro e à retração dos investimentos levaram à redução da acumulação urbana veiculada pelos grandes projetos, tendo em vista que o mercado imobiliário aparece como principal motor da crise.

É no contexto temporal de 2009 que ocorre a mais importante crise econômica e financeira mundial desde o final da Segunda Guerra Mundial. Para Chesnais (2010, p. 26):

[...] Essa crise começou no final de julho de 2007 e sofreu um salto qualitativo em setembro de 2008. 0 discurso "nada de crise aqui" foi sustentado em certo número de países, dentre os quais o Brasil. A ideia de diferenciação internamente a uma totalidade hierarquizada ajuda a perceber as diferenças nas relações de cada país no mercado mundial. Ela permite compreender por que os ritmos de desenvolvimento e as formas, assumidas por uma crise enorme tal como a crise atual, podem eles próprios ser diferenciados. Dessa forma, The Economist pôde lançar no seu site, em 14 de setembro de 2009, um artigo longo e substancial, intitulado "Brazil and the crisis: late in, first out". 
0 autor explica que, segundo os critérios de comparação internacionais mais frequentemente utilizados, o Brasil foi bem menos atingido pela crise mundial que a maioria dos outros países, e que ele seria um dos primeiros das Américas a superá-la. (Grifos nossos)

No entanto, o horizonte otimista traçado pelo The Economist foi desfeito. 0 incessante acirramento da crise econômica brasileira em 2015 não parecia um fato esperado em 2008, quando a maior potência mundial sofria uma grave desaceleração na sua economia.

A forte aceleração da crise econômica e política brasileira entre 2015 e 2016 nos conduz à hipótese de estar havendo, por parte dos empreendedores e investidores, dificuldades de manterem os arranjos de governança que pautaram suas ações nos anos recentes, veiculados pelas parcerias público-privadas e por um modelo de empreendedorismo que deu sustentação aos grandes projetos urbanos.

Nesse cenário, há a necessidade premente por parte do capital de fazer com que os setores indutores da acumulação urbana capitalista voltem a crescer, especialmente, o mercado imobiliário dirigido às classes de alta renda, e que haja o retorno à cena dos grandes projetos urbanos metropolitanos capitaneados pelo papel do empresariamento das cidades exercido pelos governos estaduais e municipais. Dito de outro modo, a retomada dos arranjos institucionais de governança público/privada.

Restam os questionamentos: "como a dinâmica da acumulação urbana pode se manter diante da retração da produção imobiliária?" e "que efeitos podem advir sobre o espaço social e econômico das cidades brasileiras?".

\section{Grandes projetos urbanos: desafio para o futuro das cidades}

Sob a influência da onda empreendedora que assolou as nossas cidades a partir da primeira década do século $X X I$, os grandes projetos urbanos assumiram formatos diferenciados de intervenção na produção do espaço urbano. Os mais significativos configuraram-se na presença dos condomínios residenciais fechados; nos megaeventos esportivos, envolvendo a construção de equipamentos e projetos imobiliários; nos projetos de reabilitação de áreas portuárias e/ou centrais; e nas operações urbanas. 0 denominador comum de todos eles foram os investimentos fundados nas parcerias público-privadas como meio da ampliação da valorização do território e da especulação imobiliária, em detrimento da reprodução das desigualdades sociais nas grandes cidades brasileiras (Compans, 2005; Leal, 2003).

Os sonhos do empresariamento foram sendo diluídos à medida que se intensifica a crise americana em 2008, induzida pela crise imobiliária. Mas, até lá, os grandes projetos urbanos foram enaltecidos por arquitetos e planejadores e por gestores públicos e empresários do mercado imobiliário involucrados em sua bolha fictícia.

"Em sua 12a edição, o Prêmio de Projetos Arquitetônicos do Futuro, ou Mipim, é a única competição que se concentra exclusivamente em projetos futuros - ela premia projetos não construídos ou incompletos". A concepção arquitetônica e urbanística de alguns dos grandes projetos premiados nesse Evento já 
demonstra o sentido de ousadia e utopia que os eles carregam e a provável influência que passam a exercer. A grandiosidade e o estilo arrojado levam, muitas vezes, ao distanciamento da feição urbana das cidades para as quais são projetados, apesar da beleza nos traços e nas cores. As Figuras 1 e 2 dão a dimensão da imponência desses projetos, os quais não demonstram, no entanto, explicitamente os seus impactos para o futuro das cidades.
A emergência de Grandes Projetos Urbanos no caso do Brasil tem estado associada nos anos recentes à presença de megaeventos esportivos, a exemplo do Porto Maravilha no Rio de Janeiro, cidade-sede dos Jogos Olímpicos de 2016. Inúmeras têm sido as críticas aos aspectos da monumentalidade que carregam, às suas marcas de empresariamento e similitudes em relação a outros projetos de "sucesso" executados em outras cidades, a exemplo de

Figura 1 - Projeto Lago Paojiang, em Shaoxing, na China

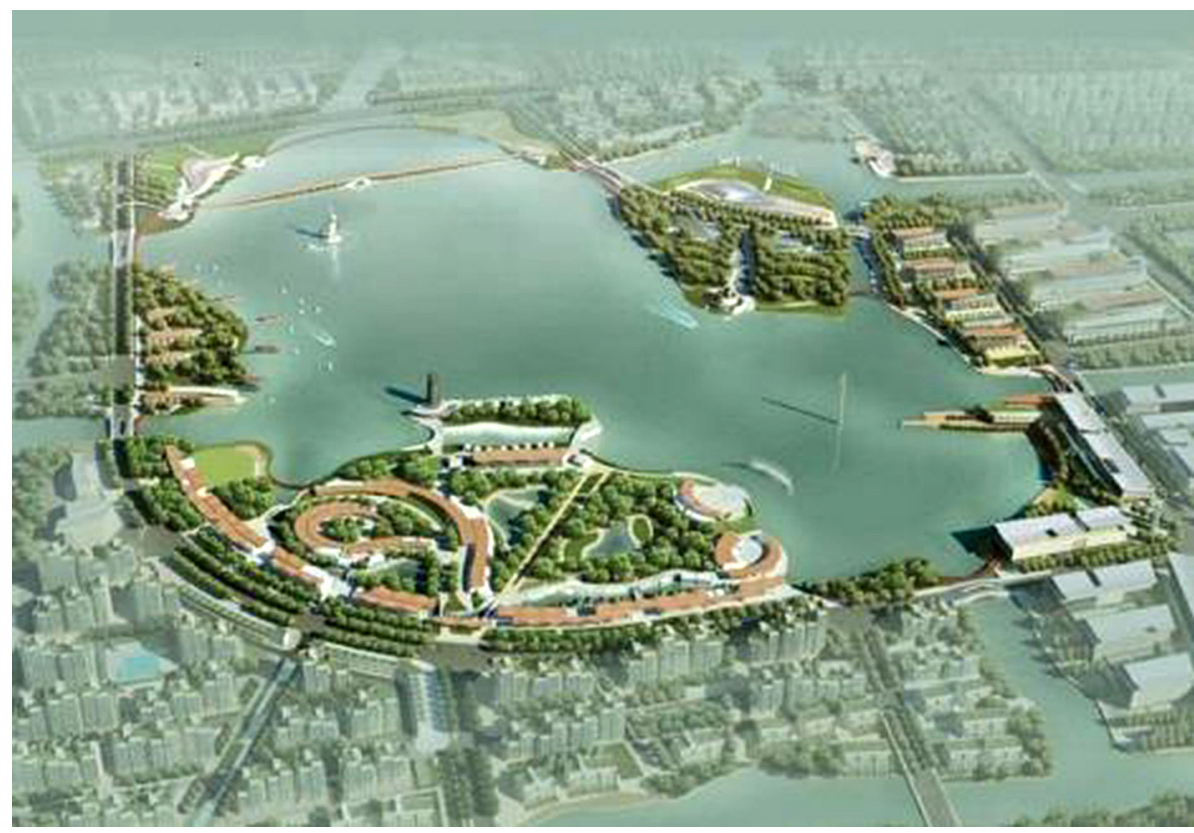

Fonte: Disponível em http://www.arquiteturaene.com.br/2014/03/premio-de-projetos-arquitetonicos.html. Acesso em: 22 dez 2016.

Observação: projetovencedor na categoria de Grandes Projetos Urbanos, criado pelo escritório Paul Kukez Architecture com a CRJA Landscape Architects e a Green Design Union. 
Figura 2 - Projeto para EilandVeurLent em Nijmegen, Holanda

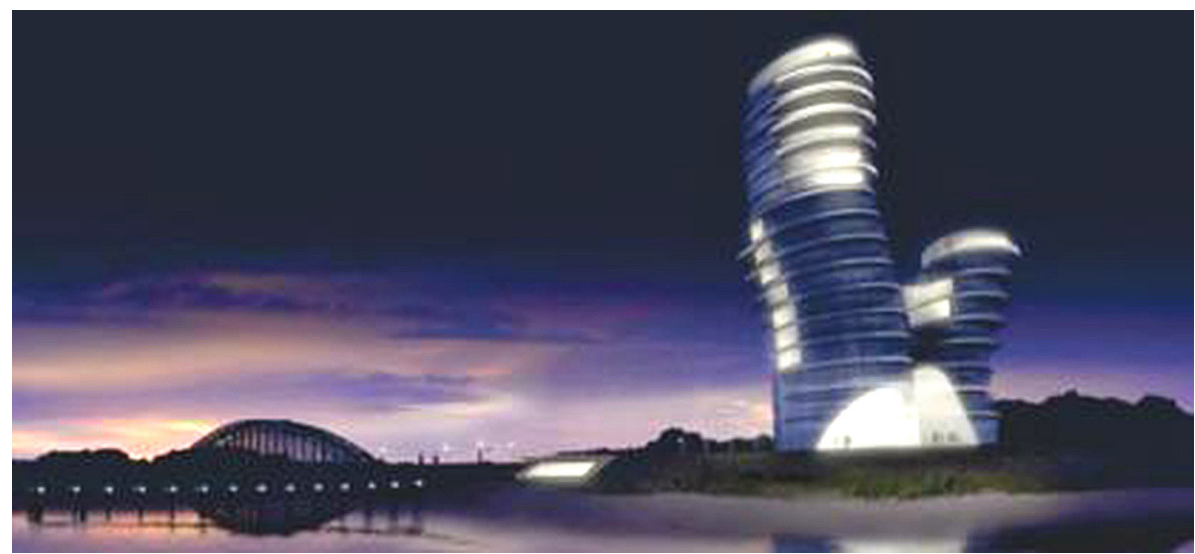

Fonte: Disponível em http://www.arquiteturaene.com.br/2014/03/premio-de-projetos-arquitetonicos.html. Acesso em: 22 dez 2016.

Observação: Projeto vencedor na categoria de Regeneração e Plano Diretor, criado pelo escritório Baca Architects. 0 projeto prevê a construção de um prédio residencial de 70 metros e uma nova passarela.

Barcelona, espelho de intervenção bem-sucedida. No entanto, os altos custos de investimentos e o baixo retorno social fazem do projeto Porto Maravilha um protótipo de cidade-mercado, no qual o beneficiamento, por parte do Estado, aos interesses dos proprietários fundiários e promotores imobiliários fortaleceu enormemente a acumulação urbana. As Figuras 3 e 4 ilustram a nossa afirmação.

Na Região Metropolitana do Recife, a presença de grandes projetos urbanos se acelera em meados desta década, por meio de fortes investidas do mercado imobiliário, tendo sido inaugurados, na administração pública municipal e estadual, novos formatos de governança empreendedora, fundados nas Parcerias Público-Privadas (PPP) e em Consórcios Corporativos Privados. Uma série de intervenções urbanas, inicialmente de forma tímida, vai tomando vulto. Tais intervenções são lideradas pelas corporações imobiliárias locais e nacionais.
Alguns desses projetos já foram implantados, tendo se destacado pelo seu porte, como são os casos do Praia do Paiva, das Torres Gêmeas do Cais de Santa Rita, do Shopping Rio Mar e da Via Mangue. Já outros estão em andamento ou foram licenciados, a exemplo do Convida Suape, do Projeto Multiuso Recife e do Projeto Novo Recife.

A ganância de valorização concentrada, inicialmente, em bairros nobres, como Boa Viagem, hoje marcado por intensa verticalização, desloca-se para a região litorânea sul da metrópole recifense, no afã de atender à demanda do chamado mercado imobiliário turístico caracterizado pela associação da atividade hoteleira e residencial, presente nos grandes resorts.

Saturada a procura pelos empreendimentos litorâneos, novas convenções urbanas são constituídas, já se observando uma nova tendência de mobilidade territorial em direção 
Figura 3 - Porto Maravilha - Rio de Janeiro - Simulação

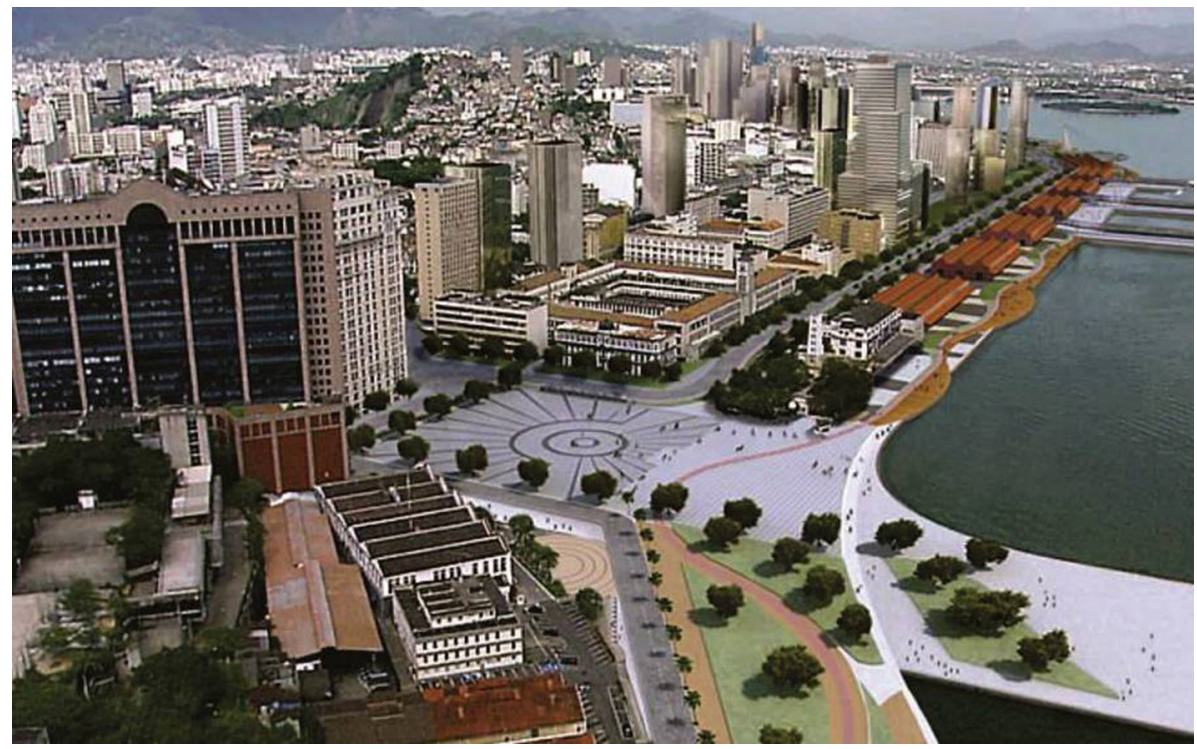

Fonte: Disponível em http://www.portomaravilha.com.br/web/sup/simulacao. Acesso em: 15 dez 2016.

Figura 4 - Galeria: Praça Mauá

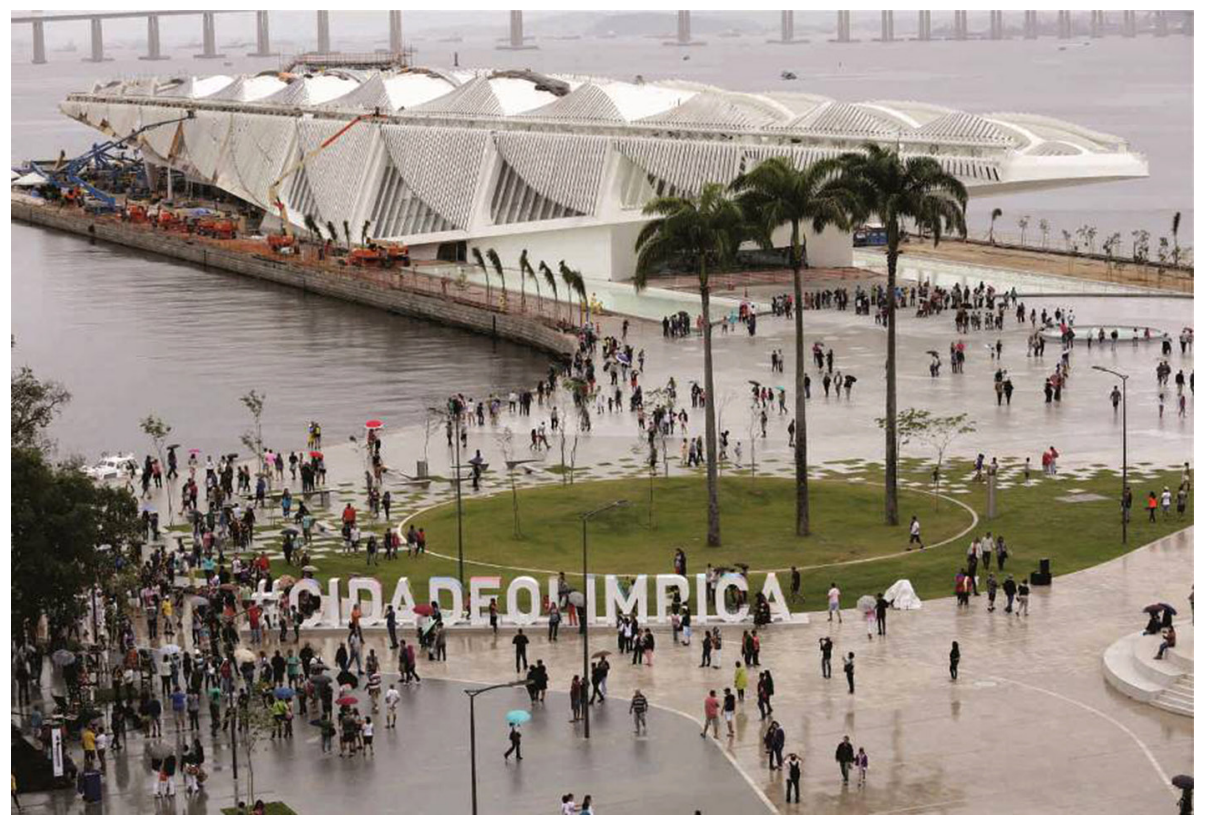

Fonte: http://www.portomaravilha.com.br/web/sup/simulacao.aspx. Acesso em: 15 dez 2016. 
Figura 5 - Empreendimentos de impacto projetados para Área Central do Recife

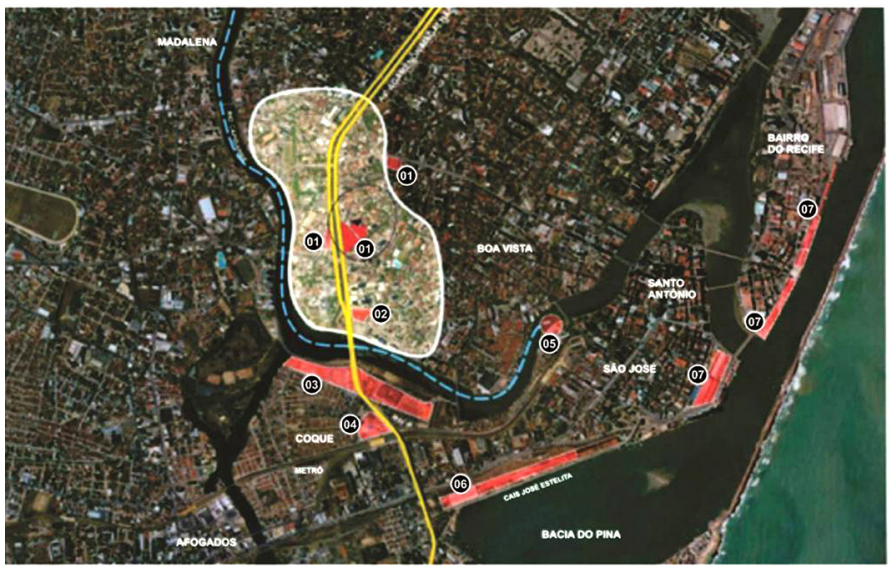

01) Multiuso Recife

02) Rio Ave Corporate Center

03) Pólo Jurídico

04) Terminal de Integração Modal (Metrô/BRT)

05) Terminal de Integração Modal (Metrô/Transporte fluvial)

06) Novo Recife

07) Porto Novo

Fonte: Projeto Multiuso Recife - Memorial de Impacto / Odebrecht, 2014.

à área central da cidade do Recife, até então pouco valorizada em termos especulativos. A Figura 5 apresenta o elenco de intervenções em curso nesse território, destacando alguns empreendimentos situados nos bairros de Recife, São José, Joana Bezerra e Boa Vista.

Os empreendimentos de maior impacto na região central são os projetos Multiuso Recife e o Novo Recife. 0 primeiro, de autoria da Construtora Odebrecht Realizações Ltda., propõe-se a ser um empreendimento inovador, orientando-se segundo um programa arquitetônico-urbanístico que prevê funções de usos múltiplos: empresarial corporativo, lojas comerciais, estacionamento de veículos e espaços para reuniões de grupos corporativos e convenções.

Este programa diferenciado e complementar tem na integração decorrente do Projeto Arquitetônico a sua mais importante característica, em razão da utilização de imóveis situados em duas quadras, resultando em duas glebas distintas com $12.169,40 \mathrm{~m}^{2}$ para a gleba contida na quadra formada pela Av. Agamenon Magalhães, Rua Jaguapitã, Rua das Fronteiras e Rua do Paissandu, e, ainda, a gleba com $6.791,86 \mathrm{~m}^{2}$ contida na quadra formada pela Rua das Fronteiras, Rua do Paissandu e Rua Mário Domingues. (Projeto Multiuso Recife - Memorial de Impacto / Odebrecht, 2014)

0 projeto de maior impacto territorial e político proposto para área central do Recife é o do Novo Recife, de responsabilidade do Consórcio Novo Recife, integrado pelas empresas Queiroz Galvão, Ara Empreendimentos, GL Empreendimentos e Moura Dubeux Engenharia, e apresenta um formato de gestão de cooperação consorciada. As articulações público-privadas e os arranjos de governança nele estabelecidos foram marcados por intensos conflitos entre os atores: poder público 
municipal, movimentos sociais e o mercado imobiliário. 0 projeto veio à tona mesmo com as fortes disputas travadas pelos movimentos junto aos representantes públicos e privados, tendo como motivação principal a luta pelo espaço público e pelo direito à cidade, contra a especulação imobiliária. 0 movimento liderado pelos grupos "Direitos Urbanos" e "Ocupe Estelita" tinha como alvo das reivindicações a proteção histórico-cultural-ambiental e urbana-territorial da área do Cais José Estelia, destinada à construção do empreendimento, já que o projeto previa intensa verticalização, impactando diretamente sobre a área tombada pelo Iphan e sobre o ambiente natural e construído. 0 movimento teve repercussões locais e internacionais, envolvendo intelectuais de renome, como David Harvey, professores universitários, artistas e cidadãos (Figura 6).
0 Conselho de Desenvolvimento Urbano da Cidade do Recife (CDU), cumprindo a sua função de fórum de negociação da política urbana municipal, foi a arena na qual se procederam os pontos de embates principais, tais como: o leilão realizado para cessão do terreno ao consórcio, cuja legalidade do processo foi questionada pelo Ministério Público Estadual; a intensa verticalização construtiva, já que 0 projeto previa a construção de 12 torres acima de 40 pavimentos; a reestruturação do sistema de infraestrutura e mobilidade urbana no local; e a relação entre os gestores públicos com os segmentos do mercado e o privado. Em 2016, o projeto, em novo formato, foi aprovado com a anuência de membros daquele Conselho. De acordo com as modificações introduzidas, prevê a construção de um complexo com atividades de habitação, comércio, serviços e lazer.

Figura 6 - Ato de Apoio ao Movimento Ocupe Estelita em novembro de 2014

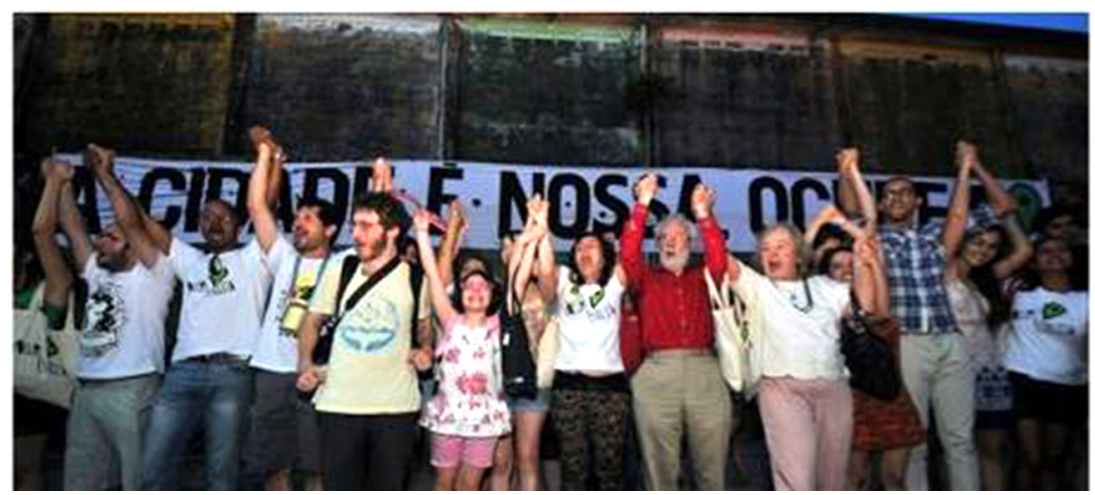

Fonte: Arquivo do Núcleo de Estudos em Gestão Urbana e Políticas Públicas - Nugepp (2014). 
Estão previstas 1.042 unidades habitacionais, distribuídas em 14 tipologias (apartamentos com área de 36 a $280 \mathrm{~m}^{2}$ ), duas unidades empresariais, com 205 salas de escritórios, duas unidades hoteleiras, com oferta de 600 leitos, e um centro de convenções e eventos, além de biblioteca pública, quadras poliesportivas, entre outros equipamentos (Figuras 7 e 8).

Figura 7 - Proposta do Projeto Novo Recife 2016

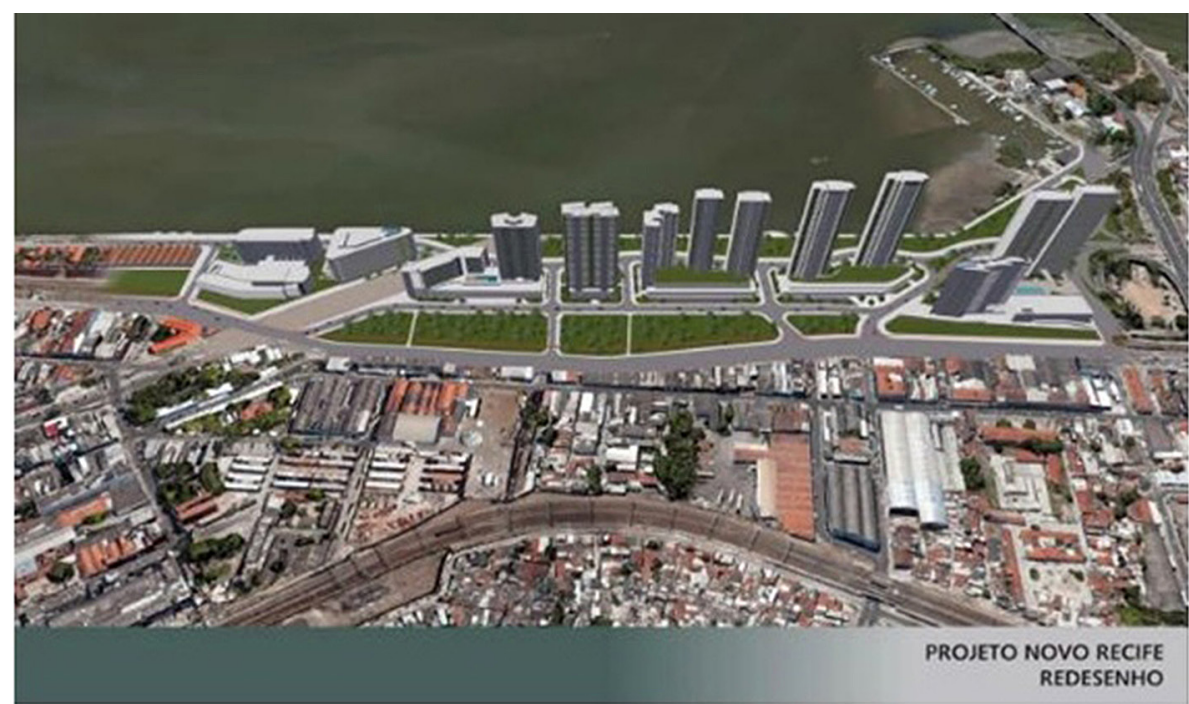

Fonte: Disponível em: http://www.novorecife.com.br/. Acesso em: 20 out 2016.

Figura 8 - Projeto Novo Recife 2016
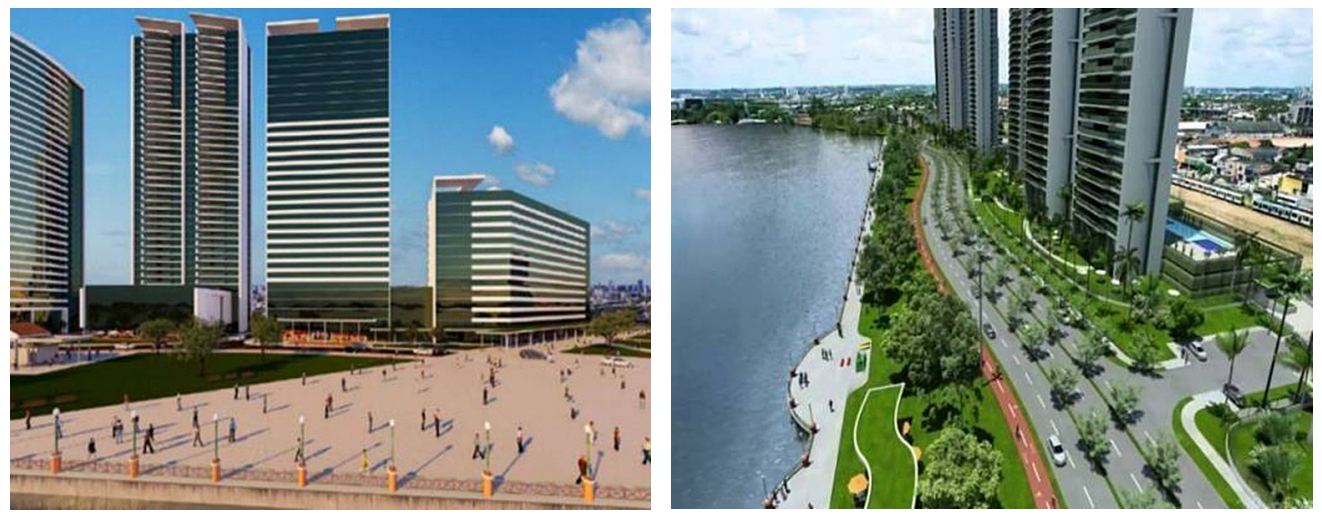

Fonte: Disponível em: https://www.google.com.br/search?q=projeto+novo+recife+2015. Acesso em: 15 out 2016. 
Atualmente, os dois projetos citados encontram-se paralisados por conta da crise econômica que provocou forte retração no mercado imobiliário nacional e local, acirrada pela crise política, em face do envolvimento, nas investigações da Operação Lava Jato, das principais empresas construtoras e imobiliárias do País.

\section{A retração acumulação urbana na Região Metropolitana do Recife}

Neste item, tentaremos evidenciar algumas das características da retração do mercado imobiliário, observando, com base nas análises da Ademi sobre o Índice de Velocidade da Vendas (IVV), o perfil de oferta, lançamentos e vendas no período 2014 a 2016, tendo como exemplo a Região Metropolitana do Recife. Nosso intuito é demonstrar, de forma sucinta, que o fato de o mercado sofrer abalos, particularmente em 2016, evidenciados pelos poucos lançamentos e pela baixa procura, exigiu por parte dos agentes econômicos, convenções e pactuações no sentido de enfrentamento da crise econômica. Artifícios de marketing e novos formatos de negociação não foram suficientes para enfrentamento e superação da crise que tem características estruturais e sistêmicas.

Nos anos de 2014 e 2015, as ofertas totais de imóveis chegaram a apresentar ligeira alta, provavelmente, por conta do programa Minha Casa Minha Vida, sofrendo queda mais acentuada em 2016, com a retração daquele Programa e o acirramento da crise econômica e política. A média da oferta ano foi mais intensa em 2015, reduzindo-se em 2016 (Figuras 9, 10 e 11).

No ano de 2016, as vendas totais do mercado imobiliário na RMR atingiram a média anual de 351 imóveis, contra 311, em2015, e 503, em 2014. Enquanto a média anual dos lançamentos foi de 212, em2016; 227, em 2015, e 554, em 2014. Segundo a mesma fonte, entre 2014 e 2016, houve um recuo de lançamentos de $61,7 \%$, enquanto as vendas caíram $31 \%$ no mesmo período, demonstrando ter havido estoque de imóveis em função do baixo poder de compra da população (Diário de Pernambuco, 17 e 18 de dezembro de 2016, apud IVVVIAdemi-PE - Figuras 12 e 13). 
Figura 9 - Comportamento da Oferta Imobiliária na RMR (2014-2016)

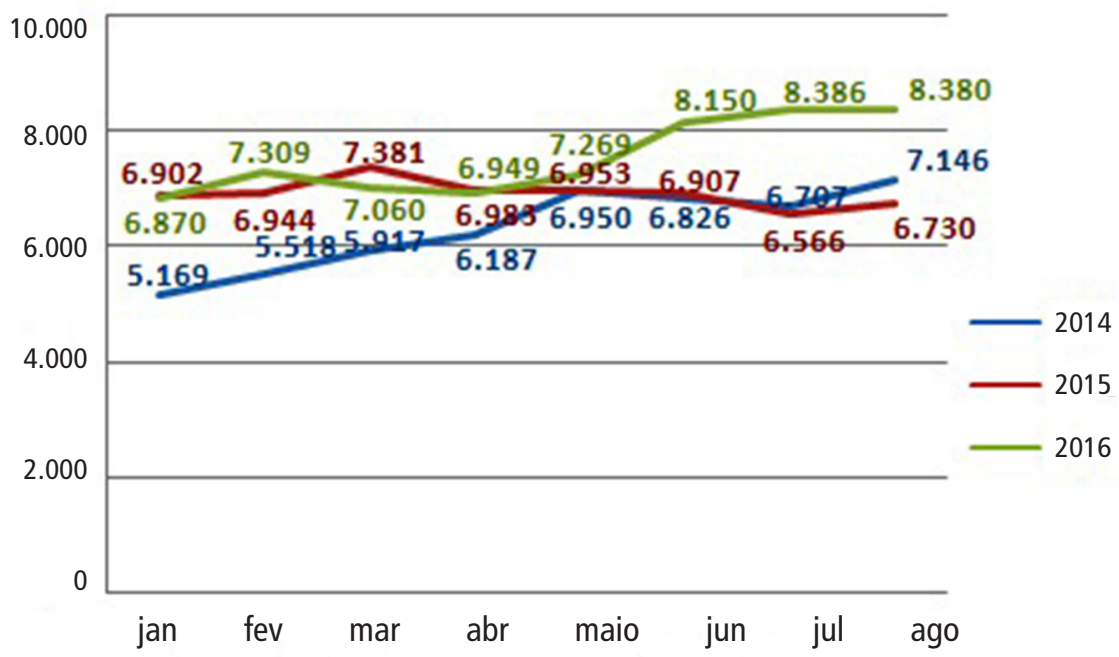

Fonte: Diário de Pernambuco de 17 e 18 de dezembro de 2016, apud IVVV/Ademi-PE.

Figura 10 - Média Ano da Oferta na RMR

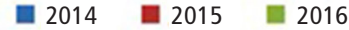

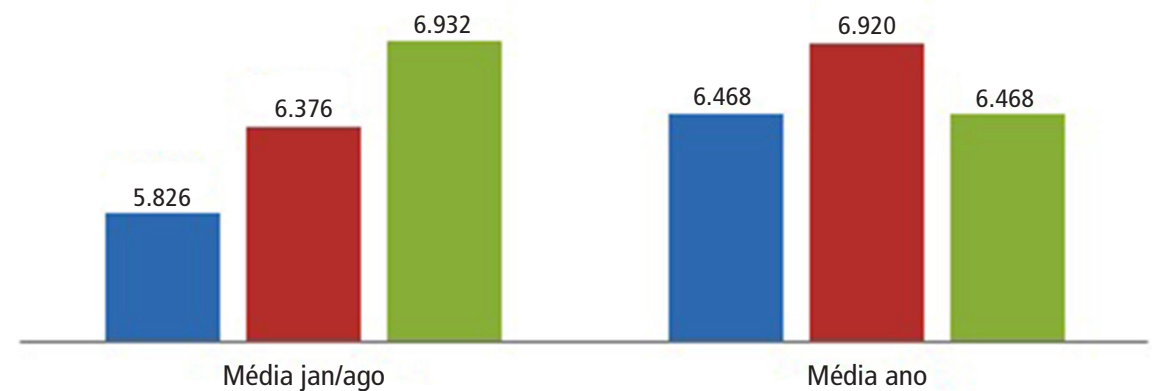

Fonte: Diário de Pernambuco de 17 e 18 de dezembro de 2016, apud IVVVIAdemi-PE. 
Figura 11 - Lançamentos Imobiliários na RMR (2014-2016)

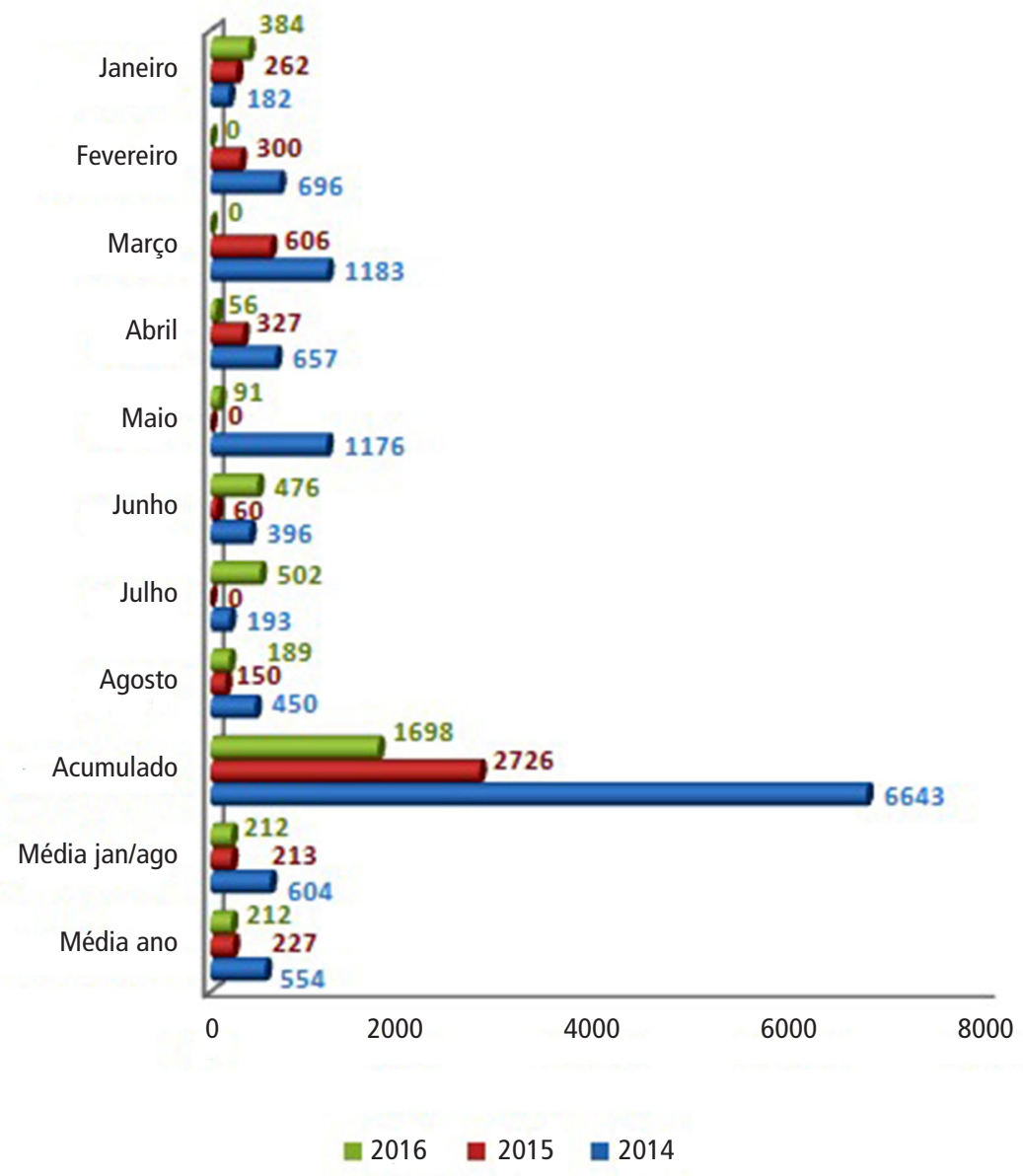

Fonte: Diário de Pernambuco, de 17 e 18 de dezembro de 2016, apud IVVV/Ademi-PE. 
Figura 12 - Vendas do Mercado Imobiliário na RMR

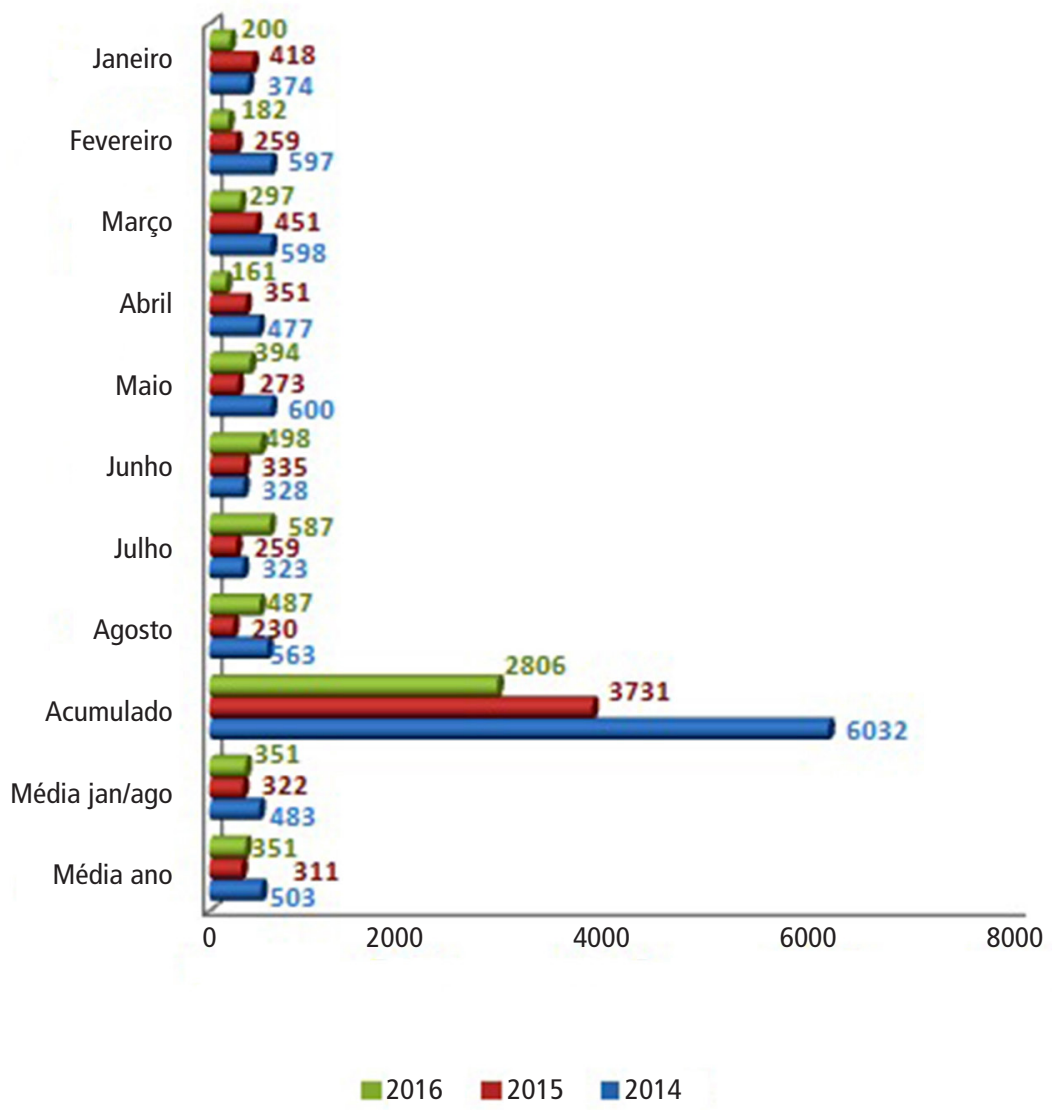

Fonte: Diário de Pernambuco, de 17 e 18 de dezembro de 2016, apud IVVV/Ademi-PE. 
Figura 13 - Relação vendas e lançamentos no mercado imobiliário na RMR

Lançamentos média ano

Vendas totais média ano

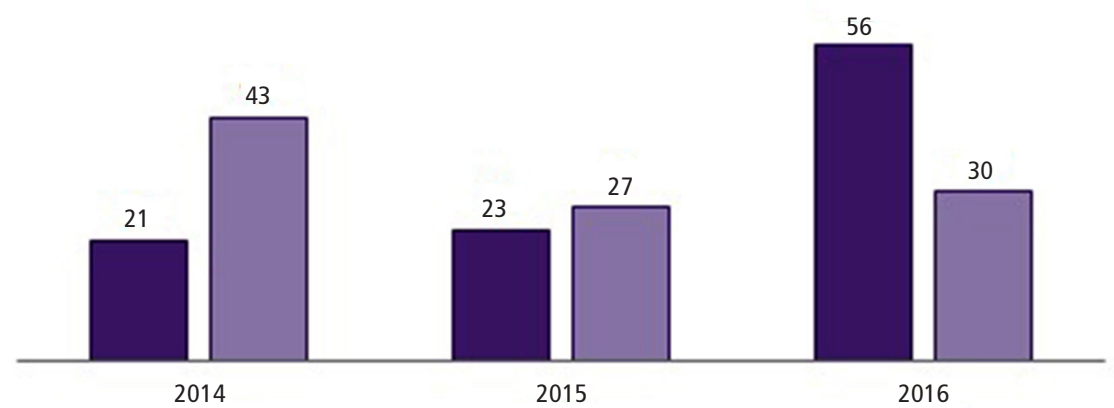

Fonte: Elaborado pela autora a partir de dados publicados no Diário de Pernambuco, de 17 e 18 de dezembro de 2016, apud IVVVIAdemi-PE.

\section{Conclusões}

A breve leitura sobre o momento de retração do mercado imobiliário, diante da crise econômica e de governabilidade do Estado brasileiro, aponta para algumas constatações a serem reforçadas através de pesquisa mais aprofundada sobre outras variáveis que implicariam maior proximidade do objeto, não viável neste artigo, como a necessidade de mensurar, por exemplo, a dinâmica do comportamento do mercado imobiliário em outras metrópoles e os níveis de seus impactos sobre a produção do espaço nacional. ${ }^{1}$

0 fato é que se observa, nos territórios metropolitanos, uma paralisia no mercado de construção civil, atingindo particularmente as grandes empresas. Essa estagnação, decorre, por um lado, da ausência da contrapartida dos investimentos públicos, na medida em que as administrações municipais veem o dia a dia dos seus gestores de cuia na mão, em busca de recursos da União. Esses sintomas da Retração do Mercado Imobiliário são evidenciados na interrupção dos grandes projetos urbanos e dos arranjos de governança empreendedora que guiavam as ações dos estados e municípios. Por outro lado, a política neoliberal do atual governo federal tem favorecido o mercado financeiro, deslocando os investimentos a serem aplicados na indústria, nos serviços e no provimento de políticas públicas na área social, incluindo o setor habitacional. Por sua vez, as parcerias público-privadas são afetadas pela 
crise financeira, levando os investidores imobiliários a ficarem impossibilitados, ora de se associar ao Estado para levar a frente as ações de empresariamento que deram sustentação aos grandes projetos urbanos, ora de dar continuidade aos programas habitacionais voltados para população de baixa renda, pela via do Programa Minha Casa Minha Vida.

Enquanto a roda financeira gira em torno de si mesma, os grandes empresários do setor da construção civil estão enjaulados, à espera da única saída que lhes é oferecida. Ou se tornam delatores, ou suas empresas correm o risco de falência, triturando-se em cacos de vidro que provavelmente não serão mais colados. As poucas oportunidades que podem ser oferecidas para o retorno da acumulação urbana no setor imobiliário e a consequente geração de emprego e renda só serão possíveis, a nosso ver, com a restauração do estado social e o incentivo à ampliação de emprego e renda, pela via do próprio marcado imobiliário.

Conclui-se que, diante do panorama da crise de Estado e da economia capitalista, o mercado imobiliário brasileiro, maculado pelo rastro infrator da corrupção, termina não resistindo às teias da crise política, retraindo sua capacidade produtiva e de investimentos, atingindo a dinâmica da acumulação em face da incapacidade do capital em manter os fundamentos estratégicos da geração do valor e da mais-valia urbana nas cidades.

\section{Suely Ribeiro Leal}

Universidade Federal de Pernambuco, Departamento de Arquitetura e Urbanismo e Programa de Pós-Graduação em Desenvolvimento Urbano. Recife, PE/Brasil.

suelyleal@terra.com.br

\section{Nota}

(1) Projeto de Pesquisa PQ/ CNPq, processo 306285/2016-9, Chamada: PQ 2016. 


\section{Referências}

ABRAMO, P. (2001). A cidade caleidoscópica. Rio de Janeiro, Bertrand.

(2007). A cidade com-fusa: A mão inoxidável do mercado e a produção da estrutura urbana nas grandes metrópoles latino-americanas. Revista Brasileira de Estudos Urbanos e Regionais, v. 9 , n. 2, pp. 25-54.

ANDRADE, A. e ROSSETTI, J. P. (2009). Governança corporativa: fundamentos, desenvolvimento e tendências. São Paulo, Atlas.

BENKO, G. (1999). "Marketing et territoire". In: FONTAN, J.; KLEIN, J. e TREMBLAY, D. Entre la métropolisation et le village global. Québec, Presses de I'Université du Québec.

CHESNAIS, F. (1996). A mundialização do capital. São Paulo, Xamã.

(2010). “Alguns elementos sobre o capitalismo contemporâneo e a crise econômica e financeira mundial". In: LEAL, S. e LACERDA, N. (orgs.). Novos padrões de acumulação urbana na produção do habitat: olhares cruzados Brasil-França. Recife, Editora Universitária UFPE.

COMPANS, R. (2005). Empreendedorismo urbano: entre o discurso e a prática. São Paulo, Editora Unespe.

HARVEY, D. (1993). Condição Pós-Moderna. São Paulo, Loyola.

(1996). Do gerenciamento ao empresariamento: a transformação da administração urbana no capitalismo tardio. Espaço \& Debates-Revista de Estudos Regionais e Urbanos, n. 39. Cidades: estratégias gerenciais, Ano XVI. São Paulo, Núcleo de Estudos Regionais e Urbanos.

(2004). Espaços de esperança. São Paulo, Loyola.

(2005). A produção capitalista do espaço. São Paulo, Annablume.

(2009). O novo imperialismo. São Paulo, Loyola.

LEAL, S. M. R. (2003). "Fetiche” da participação popular: novas práticas de planejamento, gestão e governança democrática no Recife-Brasil. Recife, Companhia Editora de Pernambuco - Cepe.

(2006). Produção imobiliária no processo de organização do espaço metropolitano do Recife. Recife, Pesquisa do Nugepp/MDU/CNPq.

(2008a). Vetores da acumulação urbana na constituição de novos territórios do mercado imobiliário na Metrópole do Recife. Recife, Nugepp/MDU.

(2008b). Acumulação urbana, mercado imobiliário e suas derivações no espaço Metropolitano do Recife. Recife, Nugepp/MDU.

LEFÈVRE, C. (2004). Paris et lês grandes agglomérations occidentales: comparaison dês modèles de gouvernance - Barcelone, Berlin, Lisbonne, Londres, Madrid, Manchester, Milan, Montréal, Rome, Stuttgart, Toronto. Paris, Mairie de Paris, Extramuros.

NOVAIS LIMA, JR., P.; OLIVEIRA, F. L.; SÁNCHEZ, F. e BIENENSTEIN, G. (2007). Grandes projetos urbanos: panorama da experiência brasileira. In: XII ENCONTRO NACIONAL DA ANPUR. Anais. Belém, Anpur.

OLIVEIRA, F. L. de (org.) (2012). Grandes projetos metropolitanos: Rio de Janeiro e Belo Horizonte. Rio de Janeiro, Letra Capital. 
SANTOS JÚNIOR, O. A. dos (2015). Democracia e governo local: dilemas da reforma municipal no Brasil. Rio de Janeiro, Letra Capital.

SANTOS JÚNIOR, O. A. dos; GAFFNEY, C. e RIBEIRO, L. C. de Q. (orgs.) (2015). BRASIL [recurso eletrônico]: os impactos da Copa do Mundo 2014 e das Olimpíadas 2016. Rio de Janeiro, E-papers.

SASSEN, S. (1998). As cidades na economia mundial. São Paulo, Studio Nobel.

VAINER, C. (coord.); OLIVEIRA, F. L.; NOVAIS LIMA JR., P.; SÁNCHEZ, F.; BIENENSTEIN, O. A.; FIX, M.; MOURA, R. e FERNANDES, A. M. (2006). Grandes projetos urbanos: o que se pode aprender com a experiência brasileira. Relatório técnico. Rio de Janeiro, LILP e IPPUR/UFRJ.

\section{Sites}

http://www.arquiteturaene.com.br/2014/03/premio-de-projetos-arquitetonicos.html

http://www.diariodepernambuco.com.br

http://www.google.com.br/search?q=projeto+novo+recife+2015

http://www.novorecife.com.br

http://www.portomaravilha.com.br/web/sup/simulacao.aspx

http://www.selurb.recife.pe.gov.br/

Texto recebido em 26/dez/2016

Texto aprovado em 15/mar/2017 
